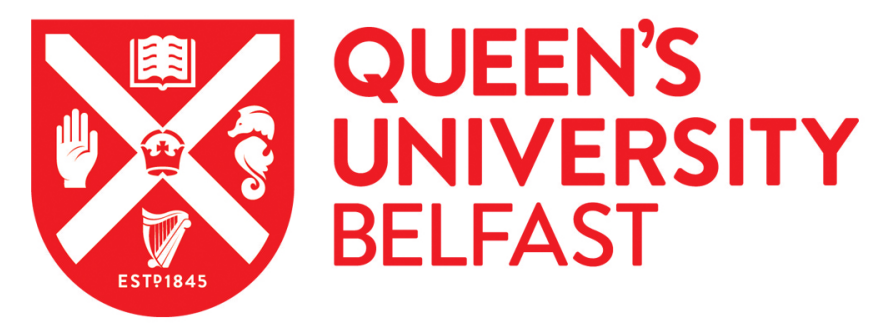

\title{
Psychosocial Needs of Bisexual People: Findings from a Mixed- Methods Research Study
}

McCann, E., \& Brown, M. (2020). Psychosocial Needs of Bisexual People: Findings from a Mixed-Methods Research Study. Issues in Mental Health Nursing. https://doi.org/10.1080/01612840.2019.1710007

Published in:

Issues in Mental Health Nursing

Document Version:

Peer reviewed version

Queen's University Belfast - Research Portal:

Link to publication record in Queen's University Belfast Research Portal

Publisher rights

(c) 2020 Informa Healthcare. This work is made available online in accordance with the publisher's policies. Please refer to any applicable terms of use of the publisher.

\section{General rights}

Copyright for the publications made accessible via the Queen's University Belfast Research Portal is retained by the author(s) and / or other copyright owners and it is a condition of accessing these publications that users recognise and abide by the legal requirements associated with these rights.

Take down policy

The Research Portal is Queen's institutional repository that provides access to Queen's research output. Every effort has been made to ensure that content in the Research Portal does not infringe any person's rights, or applicable UK laws. If you discover content in the Research Portal that you believe breaches copyright or violates any law, please contact openaccess@qub.ac.uk. 


\title{
Psychosocial needs of bisexual people: findings from a mixed-methods research study
}

\begin{abstract}
More attention has recently been paid to the unique experiences and health needs of LGBTQ+ people. To date, there has been a limited focus on the distinct psychosocial needs of bisexuals. A larger mixed-methods study explored the wider needs of a LGBTQ+ cohort. The aim of this paper is to report the specific experiences of bisexuals and highlight their distinct psychosocial issues and concerns. The online survey instrument contained Likert-scale and qualitative questions and was completed by a total sample of LGBT people $(n=125)$, of which 19 participants self-identified as bisexual. The qualitative responses of the bisexuals were extracted and analyzed separately to identify emergent themes that were: accessing responsive services, culturally competent services, supports and interventions, and knowledge, skills and confidence. The study findings inform and enhance the understanding of the issues that impact upon the health and well-being of bisexuals, thereby contributing to promoting the wider social inclusion and human rights agenda by guiding mental health service developments, policy initiatives, education provision and future research.
\end{abstract}

\section{Keywords:}

Bisexuality, mental health, psychosocial interventions, social inclusion, human rights 


\section{INTRODUCTION AND BACKGROUND}

There is a growing and evolving body of international research evidence involving LGBTQ+ populations and their health requirements (Caceres et al. 2019, Hafeez et al. 2017, Hickson et al. 2016, McCann \& Brown 2019, Smith et al. 2018). However, the needs of sub-populations are often presented homogenously within existing research studies. There is a clear requisite by researchers to conduct studies that separates out the constituent groups to determine the distinct and unique needs and concerns of each sub-population. This includes focusing on bisexuals to identify their specific healthcare concerns and needs and the responses required (Castro et al. 2019, Rahman et al. 2019, Taylor 2018). Existing studies indicate that bisexuals have poorer mental health outcomes than other sexual minority groups and heterosexuals, an issue that may be exacerbated by internalised biphobia (Oginni et al. 2019, Van Beusekom 2018). The reasons behind the higher prevalence rates of mental ill-health in the bisexual population remains elusive and largely unexplored.

Bisexuality is defined as 'a stable pattern of attraction to both sexes in which the specific balance of same-sex to other-sex desires necessarily varies according to interpersonal and situational factors.' (Diamond 2008, p.12). Yoshino (2000) posits that bisexuality can involve identity, attraction and behaviour, with research participants incorporating any of these elements into their experiences. In a study using this three axes process, 5.8\% of male and $14.2 \%$ of female participants reported non-monosexual attraction with $5.6 \%$ of men and $13.2 \%$ of women having sexual experiences with more than one gender.

The concept of minority stress has significance in relation to the psychosocial experiences of bisexual people (Feinstein \& Dyar, 2017, Frost et al. 2015). In terms of mental ill-health, the Australian Longitudinal Study on Women's Health identified that bisexual women had significantly higher levels of depression, stress, anxiety and self-harm when 
compared to heterosexual females (Hughes et al. 2010). In a Canadian study, $45.4 \%$ of bisexual participants reported lifetime suicidal ideation compared with $29.5 \%$ of lesbians and $9.6 \%$ of heterosexuals (Steele et al. 2009). Only one study exists that reports suicidality figures for bisexual male respondents with $34.8 \%$ seriously contemplating suicide compared with $25.2 \%$ of gay men and $7.4 \%$ of heterosexual men (Brennan et al. 2010). Limited available data compares men and women although bisexual women were found to have higher incidences of diagnosed mental health problems than men in one US study (Bostwick et al. 2014). Despite the higher incidences of health issues and support needs, accessing appropriate mental health services was often experienced as problematic. Negative attitudes displayed by practitioners presents barriers to help-seeking, hence bisexuals were less likely to be 'out' to their general practitioner. In one study, participants reported receiving inappropriate sexual comments, biphobic or bi-negative attitudes and inappropriate care. Often practitioners were viewed as lacking knowledge about bisexuality, with some viewing bisexual behaviour as 'unhealthy', thereby invalidating bisexuality as a legitimate sexual orientation (Dobinson et al. 2005, Ebersole et al. 2018). This can lead to increased invisibility and erasure, exacerbate social exclusion, discrimination and marginalisation (la Roi et al. 2019), thus impacting negatively on mental health and well-being (Savin-Williams et al. 2018).

People who identify as bisexual have been found to experience disadvantage with diminished levels of social support than gay and lesbian people (Ross et al. 2010). Some studies report that bisexuals often feel unsupported and unacknowledged by their friends, family and wider society. Bisexual-specific groups rarely exist, however, where they are available, there positive attributes, such as peer-support and shared identity, are acknowledged. Some bisexual people feel accepted in the LGBT community and some in the heterosexual community, while many people report not being accepted anywhere. A matter of 'bi's being too straight for the gay community and too queer for the straight community' according to one commentator 
(Taylor 2018). This lack of community can lead to loneliness, disconnection and isolation. Increased social connection can lead to validation of identity, relief, release, decreased internalised homophobia and increased resilience (Chard et al. 2015). Feeling part of a community and having a sense of belonging within social groups is positively correlated with enhanced mental health and well-being. However, there is a distinct lack of research studies that examine the relationship between the mental health experiences of bisexual people and identity, labels and 'coming out.' Studies involving gay and lesbian groups demonstrated that successful 'coming out' has been associated with positive mental health benefits and the development of resilience and positive coping strategies (Ross et al. 2010). There is a need to better understand why bisexual people experience psychosocial challenges than those of other sexual and gender identities (McCann \& Brown 2018; Taylor 2018). Therefore, the aim of the paper is to identify and present the pertinent issues and concerns for bisexual people and present recommendations for mental health practice developments.

\section{STUDY METHODS}

\section{Aim and questions}

The original wider study involving LGBT+ participants $(n=125)$ investigated their mental health experiences and needs using a mixed-methods research design, with the main findings published elsewhere (McCann \& Sharek 2014). The qualitative data specific to the bisexual participants was extracted and analyzed separately due to the uniqueness of their views and experiences. Therefore, the aim of the current study was to examine the views and experiences of bisexuals in relation to their distinct psychosocial support needs. The study questions were:

1. What are the views and experiences of bisexuals in relation mental health services?

2. What are the psychosocial support needs of bisexuals?

\section{Design}


The study used mixed-methods including a survey design that contained qualitative semistructured questions. The survey included demographic information and closed questions related to mental health experiences. A further two open-ended questions related to views and opinions of mental health services and suggestions for improvements. Participants were asked to provide any additional information regarding their views and experiences.

\section{Setting}

The study was conducted in the Republic of Ireland among adults identifying as bisexual who had experience of mental health services in community and inpatient settings.

\section{Participants and inclusion criteria}

People were invited to take part in the study if they identified as bisexual, were aged 18 years and over, and had used mental health services in the past 5 years in Ireland.

\section{Demographics and mental health concerns}

Table 1 contains the demographics and mental health concerns of the 19 bisexuals. The gender identity of the bisexual respondents was male $(n=6)$, female $(n=11)$ and transgender $(n=2)$. All but two of the participants were Irish. A majority $(n=11)$ were currently single and a significant number received treatment in outpatient settings $(n=14)$. A total of 8 participants was in the 18-24 age range; 8 in the 25-44 range and 3 were aged between $45-64$ years. No participants were over 65 years of age. The main mental health issues identified were depression and anxiety and the most frequent treatment provided was medication. Seven participants were offered some form of psychological therapy.

\footnotetext{
**Table 1 here**
} 


\section{Recruitment and data collection}

The survey instrument was developed by the research team based on existing research literature. The instrument was piloted and minor modifications made. To enable wide participation, the instrument could be completed online, by post, or telephone-interview. A multipronged strategy was adopted in order to promote recruitment to the study. First, LGBT and mental health organizations, including hospitals and clinics throughout the country, were sent packets with study information. Each packet contained a letter from the principal investigator inviting organizations to promote the study by disseminating information through posters and leaflets, and making available hardcopies of the survey instrument to potential participants. Second, LGBT and mental health organizations were sent emails requesting that they pass on the study information and survey link to their email contact lists. Finally, several major LGBT organizations within Ireland agreed to place details about the study on their social media pages.

\section{Ethical considerations}

The relevant research ethics committee provided ethical approval and all ethical and governance processes were followed throughout the study. The researchers recognized the potential sensitivity of the subject area and possibility for distress. Therefore, details of mental health support organizations and helplines were made available. All study participants provided independent informed consent.

\section{Data analysis}

The qualitative data provided by participants within the survey was anonymized and any identifying information removed. The data was systematically analyzed using thematic analysis to identify the emerging themes across and within the participant responses. Each 
response was analyzed individually and collectively to allow for the key themes to be identified (Clarke \& Braun 2017). QSR NVivo 11 software (QSR International 2015) was used to support the analysis of the data set.

\section{Analytical rigor}

The central tenet of qualitative data analysis involves the application and maintenance of robust methods of data collection, analysis and synthesis. These approaches were rigorously applied to ensure the trustworthiness, credibility and dependability of the data analysis (Lincoln \& Guba 1985; Noble \& Smith 2015). This was achieved by the research team independently and collectively by cross-checking and confirming the themes. As a result of this comprehensive process, the psychosocial experiences and support needs of the bisexual participants were identified, thereby facilitating the potential utilization and transferability of the findings (Graneheim et al. 2017).

\section{STUDY RESULTS}

Following analysis of the data, four themes emerged: (i) accessing responsive services; (ii) culturally competent services; (iii) supports and interventions; and (iv) knowledge, skills and confidence.

\section{Accessing responsive services}

The experience when accessing mental health services was seen as important for participants, influencing the way in which they believed they were perceived and responded to by health professionals. The decision to share their bisexual identity when accessing mental health services was viewed as influencing the direction of the assessment and treatment received. Some participants were of the view that their bisexual identity had no relevance in relation to 
their presenting problems and the need to access mental health services and therefore actively elected not to share it with the health professional:

It is coincidence that I identify as LGBT, and, have used mental health services in the last 5 years! For me the two are unrelated and I did not disclose my identity for discussion as it was not relevant to my mental health problems which brought me to the services. I never felt the need to hide my identity - simply it was not relevant, and I did not want 'help' with who I was at that time for that reason (P84)

For others, there were concerns that their presenting mental health concerns were misattributed to their bisexual identity, rather than their presenting problem and referral to mental health services. Participants wished to be assessed and treated as 'individuals' and not viewed as 'a box to be ticked,' and their mental health concerns responded to appropriately and sensitively, irrespective of their sexuality. As one person explained:

Acknowledge the difficulties faced by LGBTs in the community, rather than this just being a ticked box on the application form. It's a very significant factor in an individual's experience of mental health issues (P22)

For some, there was a sense that having chosen to disclose their bisexuality, their presenting mental health concerns were not taken seriously, and were quickly and inappropriately attributed to and then dismissed by the assessing health professional, as resulting from their sexual identity. One participant explained their experience:

I received very little sympathy from some psychiatrists I have seen and it has even been suggested to me that my life will stabilize when I find a man (P114)

Therefore, participants highlighted that as a result of their bisexuality they lacked a sense of belonging, a feeling which could be exacerbated within mental health services: 
....it sometimes feels as if I am neither here nor there... unbelonging... where do the bi's fit in? There must be bi groups and support - but I've yet to find them here...(P122)

\section{Culturally competent services}

Bisexual people have an expectation that health professionals within mental health services will be respectful and non-judgmental and come prepared with the pre-requisite knowledge, skills, attitudes and values to respond in a way that is supportive and person-centred. For one participant, feelings of trust within the interpersonal relationship was important:

....sharing your deepest thoughts and experiences with a medical stranger is a bit scary really...how much do you tell...and then what do you get? You really lay yourself open...feel more vulnerable I suppose... (P124)

Some participants experienced health professionals practicing in a way that appeared to invalidate their experiences that led to feelings of invisibility regarding the sharing of their bisexual identity:

When being hospitalized I did mention to the doctor that was assessing me that I was bisexual, he ignored my comment and carried on with his questions. I did not mention it again, and at no time was it ever brought up...(P12)

Other participants highlighted that the health professional suggested that 'being heterosexual' was the answer and solution to their apparent mental health problems, thereby failing to acknowledge and address the persons individual circumstances, including those related to their bisexuality: 
My shrink spent most of our sessions telling me that my illness was because I was bisexual and if I just accepted and lead a straight life everything would be OK....

There was an apparent failure to recognize the factors that led the person to seek help from mental health services in the first instance. Other participants highlighted the limited understanding of bisexuality by some health professionals, which had the effect of increasing the sense of invisibility, heteronormativity, and erasure of their sexual identity:

Professionals should never to have to question the 'authenticity' of someone's sexual preference...make it the 'norm' that the patient is not necessarily heterosexual...make identifying the person's sexuality a key part of the initial assessment and treating the response and the person with respect $(\mathrm{P} 30)$

One participant, who had a positive experience of counselling, highlighted the need for further training and education regarding the needs of bisexuals and LGBT service users more generally:

My experience with two different counsellors was not wholly negative and they didn't judge me, but I just felt that they could not relate to me or my experiences or really understand me in a way that a bisexual person can. I felt that at times there was a lack of understanding of relevant issues, like concealing your identity at work, and the daily stress of heterosexism and hearing homophobic comments, and that the counselling could have been more directive - like asking relevant questions about what it's like at work, with my family etc. I think person-centred counselling is good, but it needs more direction with bisexual and LGBT clients...(P81) 
For transgender people who are also bisexual, there were often multiple and complex presentations and needs:

...saw a psychiatrist only once who had no clue about trans and bisexuals...I had to explain everything...was totally reluctant to visit a mental health professional because of their lack of knowledge. Once stated that I was hetero, just or the record, instead of unsure about sexual identity at the time. Encountered hostility when it came to being trans and being non-heterosexually identified (P89)

\section{Supports and interventions}

A recurring theme across participant responses was a desire for access to a range of supports and treatment options. Participants wished to be able to access therapies, for example, CBT and Mindfulness. It was acknowledged that within the current health service system there was limited availability of psychological therapies, with long waiting lists. As a consequence, many participants highlighted that the only treatment option that was offered was medication, and should they wish to access psychological therapy, they would be required to self-fund this. This was not a viable option for some participants and therefore they felt obligated to accept medication as the only form of treatment for their condition:

\footnotetext{
Adjunct use of medication is an issue. Comprehensive mental health services should not be over-reliant on medication. Health professionals need to just stop giving medications as the only form of treatment (P28)
}

One study participant had experience of mental health services outside of the Republic of Ireland and was therefore able to offer a comparison between the two experiences and highlight the differences:

They [psychiatrists] were not willing to help, apart from with meds, with any other mental health issues that I was experiencing. This is very different to some to my 
experiences I had in the UK, where I did get access to CBT, counselling, psychotherapy, mindfulness etc. and was able to feel comfortable addressing LGBT issues and all free of charge $(\mathrm{P} 23)$

For one study participant, their experience of psychiatrists was particularly negative in the public health system, and they felt they had no option but to self-fund therapy in the private sector as a means to avoid medication as the only treatment option:

I have found psychiatrists in the public health services so bad that I have been forced to seek therapy outside the public health system and outside of my means (P114)

For another participant, the feeling of isolation was apparent that was in part reduced through contact with mental health services. The issue of trust in being able to disclose intimate and personal information was seen as important:

As a bisexual, isolation is a huge problem, and stress also. You need to be able to talk to someone you can trust and who will really listen and take the time to understand, within mental health services (P107)

\section{Knowledge, skills and confidence}

Health services have a responsibility to ensure that all of their policies and procedures take account of and are reflective of the needs of bisexuals thereby promoting inclusion and antidiscriminatory practice within services, including mental health. Participants were of the view that health professionals involved in their assessment, treatment and support, would have the required knowledge and skills including those related to the distinct needs of bisexuals. Therefore, education and practice development gaps need to be addressed to ensure that practitioners are appropriately prepared to respond to the needs of people from diverse groups, including bisexuals: 
I just don't think they have the skills here and I am not sure that many in the health service want to upskill and work with this population. It is hard to know or judge. I felt my mental health and bisexual issues weren't important, therefore, I was made feel I was not a priority for services... (P23)

However, some participants had poor experiences with health professionals, notably those who had been practicing in mental health services for a significant number of years:

The older the health care professional, the more narrow-minded they are and less likely to try to listen and understand, in my experience. They should be more aware of bi-relationships, listen carefully, so they can provide better advice and support, not just act on what they have read about, if they have read anything... (P44)

Participants highlighted that in order for mental health services to respond effectively to the needs of bisexuals, it is also necessary for professionals to be equipped with the appropriate attitudes and values necessary to ensure that assessment, treatment and support is respectful and responsive to the needs and circumstances of the individual:

More awareness of sexual health and its relationship to mental health would be great. There are many specific services for gay men, but when I was treated for an STI [sexually transmitted infection] as a bisexual woman, I encountered many negative reactions, including being told I couldn't contract STIs from female-female sex. My mental health was in turmoil related to this incident. The relationship between sexual health and mental health would be worth stressing, and that it's not just gay men who attend GUM [genito-urinary medicine] clinics. (P96) 
The importance of service providers acknowledging and supporting people from diverse backgrounds, that is reflected in their policies, education and practices was articulated by one participant:

....to 'LGBT proof' all policies, forms and trainings so that providers in no way assume or dismiss someone's sexual orientation or gender identity (P119)

\section{DISCUSSION}

The aim of this study was to examine the distinct psychosocial views and experiences of bisexual people and identify their support needs. The findings from the current study highlights the many challenges experienced by some bisexuals when accessing and navigating their way through mental health services. This is despite the growing and evolving evidence regarding the extent of mental ill health experienced by some bisexuals (Taylor 2018). Even when taking into account research design, methodology, sample size and aims of the available studies, the general conclusion is that bisexuals experience poorer mental health when compared to other sexually diverse groups, such as lesbians and gay men. Despite this evolving picture, the research focus on this population remains limited, with the studies that have been undertaken being restricted to Canada Australia and the Unites States (Eady et al. 2011, Flanders et al. 2019, Taylor et al., 2019). Longitudinal studies have identified that bisexual women experience high rates of previous self-harm, depression, anxiety and stress (Hughes et al. 2010). Similar findings were identified in a Canadian study that found significant rates of mood and anxiety disorders and suicidality compared with heterosexuals and lesbians (Steele et al. 2009). Studies focusing specifically on mental health of bisexual men are minimal. Of those that do exist, there is evidence of 'poor or fair' self-reported mental health and lifetime suicidality (Brenan 2010). In terms of the current study, the mental health medical diagnoses (see Table 1) are reflective of those reported in the international studies (Bostwick 2014, 
Hughes 2010, Steele et al. 2009). Affective disorders, namely anxiety and depression, were most commonly reported. This was followed by sleep disorders, substance use, eating disorders, gender identity disorder (GID) and obsessive-compulsive disorder.

It is apparent from the findings of the current study, that some people disclosed their sexual identity to the mental health professional, with negative responses broadly evident. One response was to apparently ignore the sexual or gender identity disclosure within the assessment process, thereby leaving some patients feeling disregarded and, this important element of their life, dismissed. For others, there appeared to be an over attributing of the presenting mental health concerns within the context of their bisexuality, even if the patient was of the view that their bisexual identity was unrelated to their current clinical presentation. The study findings suggest that heteronormativity appears to remain the predominant assumption held by some mental health professionals. This is exemplified by the participant who highlighted that by simply establishing a heterosexual relationship, the presenting mental health issue would somehow be ameliorated. Such a view clearly fails to recognize and acknowledge that heterosexuals too experience, within their personal relationships, situations that may negatively impact upon their mental health and well-being (Semlyen et al., 2016).

From the perspective of some bisexuals, there was the view that, as a consequence of their sexual identity, they found it difficult to situate themselves in either heterosexual or lesbian, gay and transgender communities. Furthermore, there was an apparent lack of social support networks specific to bisexuals, thereby increasing the sense of loneliness and social isolation for some. Many of the study participants referred to medication as the only treatment option offered. For those seeking psychotherapies, the only realistic alternative to medication was to self-fund therapy within the private sector. This left some who were unable to afford to fund therapy, with no treatment alternatives other than medication, despite the wider research 
evidence supporting the provision of psychological therapies (Alessi et al. 2019, Bastiampillai et al. 2019).

There have been significant strides in many countries over the past 50 years regarding the human rights of LGBTQ+ people (D'Emilio 2019). Examples such as marriage equality, adoption and fostering and employment rights exemplify this. However, in many areas across the world, lesbian, gay and transgender people continue to be actively discriminated against and in some cases subjected to physical assaults and murder (Voss 2018). The LGBTQ+ rainbow umbrella term has become synonymous with these broad populations and offers a way of conceptualizing and understanding diverse experiences and needs. What is apparent from the international research evidence regarding LGBTQ+ people, is that they are not a homogeneous group. They are in fact distinct groupings that have been drawn together under the rainbow umbrella (Savin-Williams et al. 2018). There exists established research evidence and policy developments regarding the needs, including health needs, of lesbians, gays and transgender people (McCann \& Brown 2019, Rahman et al. 2019, Smith et al. 2018). There is however, less of a research and policy focus on the distinct and unique needs, including health needs, of bisexuals. The definition of bisexuality, which involves sexual identity, attraction and behavior goes beyond sexual experiences with the same sex and therefore it is possible that some people who are bisexual may not self-identity with a bisexual identity thereby possibly limiting their help-seeking behavior. On one level, some may actively conceal their bisexual sexual identity, leading an external heterosexual life, and for others there are fears of social exclusion, stigma and discrimination (Taylor et al. 2019). Others may experience bi-phobic and bi-negative attitudes that may result in erasure and the decision to keep this part of their identity hidden. In contrast, for some, their bisexuality offers new affirming life enhancing opportunities and experiences (Rostosky et al. 2010). Within younger populations, gender and sexual identity appears to be considered more fluid, liberating and less socially constraining, 
where a bisexual identity is increasingly recognized (Miller at al. 2018). These complexities need to be more fully understood and articulated with policies that seek to respond to the cross section of sexual identities. Therefore, health policies from a public health, primary care, sexual health and mental health perspectives need to be responsive and sensitive to the diverse range of experiences and needs within the bisexual population. This is particularly important from mental health policy developments, given the emerging evidence of their psychosocial support needs, as a distinct group.

\section{Practice implications}

Participants in the current study were explicit about their hopes and expectations around accessing necessary supports and the provision of responsive care and appropriate treatments. Health professionals working in mental health services need to develop their awareness of the existence of and particular needs of bisexual people who may require inpatient and outpatient treatments and services. In order to comprehensively identify the health needs of mental health service users it is important that assessments fully incorporate elements that focus on sexual identity, beyond the broad LGBTQ+ umbrella. This creates an opportunity for mental health professionals to sensitively explore and discuss the possible link between the presenting mental health condition and with the distress that may be associated with their bisexual identity. It is critically important that mental health professionals avoid minimising and dismissing the patient's bisexual identity disclosure and ensure that it is given due regard within the biopsychosocial assessment and treatment options are reflective of the patient's comprehensive needs, beyond a mental health diagnosis and psychopharmacological intervention.

\section{Education and training issues}

Health education undergraduate preparation programs present an opportunity to include a clear focus on the needs of LGBTQ+ people and their particular psychosocial requirements (McCann \& Brown 2018). Within the delivery of LGBTQ+ health in education programs, there is a need 
to ensure that there is a clear focus on the unique needs and concerns of bisexuals. At a postgraduate training level, there is an opportunity to ensure that health professionals are adequately prepared with the knowledge and skills, attitudes and positive values necessary to provide inclusive person-centred assessment, treatment and support relevant to the needs of bisexual people. In relation to the availability of psychological therapies, there is a need to increase the number of trained therapist and improve access to therapy (Mollen et al. 2018, Peppering 2018). Within these postgraduate therapy training programs, for example, CBT, there is a need to embed and reflect the needs of LGBTQ+ people, including those who are bisexual. Addressing these issues will help to ensure there is access to therapies that is both effective and affirmative for bisexuals. Continuing professional development programs focusing on areas such as equality and diversity, anti-discriminatory practice and cultural awareness, presents an opportunity to include an LGBTQ+ focus, including a spotlight on the specific needs of bisexual people.

\section{Research implications}

From a research perspective, bisexuals within the wider context of LGBTQ+, are commonly included as a sub-population, within the wider study sample. As a consequence, it can be difficult to confidently identify within the findings and recommendations, aspects that are specific to the needs of bisexuals. A recent large cross-sectional study undertaken in Australia involving bisexuals, achieved a sample of over 2600 participants. This study highlights the feasibility of conducting large-scale studies focusing exclusively on bisexuals (Taylor et al. 2019). There remains a specific limited research focus involving bisexuals. The studies that do exist have predominantly been undertaken in Canada, Australia and the United States and highlight key issues related to the health needs of bisexual people. However, in order to more fully understand the specific needs and experiences of bisexuals, future international research 
collaborations require to be undertaken that has a clear focus on this population. Global studies involving wider LGBTQ+ samples offer an opportunity for researchers to analyze their data in relation to specific sub-populations such as bisexuals, thereby growing and evolving the evidence base of the needs of this population and the supports required to effectively meet their mental health needs.

\section{Strengths and limitations}

The study adds to a small but growing body of international research evidence regarding the distinct needs of bisexuals. It presents the views and experiences of bisexuals in Ireland and the researchers appreciate the variations in service delivery models and service user experiences internationally. A unique feature of the current study is the qualitative element of study design that enabled the bisexual participants to share their views and experiences of mental health services and their psychosocial needs. The Republic of Ireland has seen significant legislation and policy developments in recent years regarding LGBTQ+ people, and the willingness of bisexual participants to fully engage in the study is a further strength. Despite best efforts, the study did not include participants from diverse ethnic backgrounds, such as people of color or those in residential care and therefore the complete range of experiences may not be fully reflected. These limitations are recognised and acknowledged.

\section{CONCLUSION}

Bisexuals have distinct and specific care and support needs with nurses being in a strong position to shape services and provide interventions, treatments and supports that are responsive and person-centred. Nurse educators are well placed to work collaboratively with nurses in clinical practice and bisexual service user groups, where they exist, to develop and implement undergraduate, postgraduate and CPD programs that will develop the knowledge, 
skills, competence and confidence to effectively meet the needs of bisexual people within mental health services in the future.

Acknowledgements: With thanks and appreciation to the study participants who gave freely and so generously of their time.

\section{Disclosure of interest:}

The authors report no conflicts of interest. 


\section{REFERENCES}

Alessi, E. J., Dillon, F. R., \& Van Der Horn, R. (2019) The therapeutic relationship mediates the association between affirmative practice and psychological well-being among lesbian, gay, bisexual, and queer clients. Psychotherapy 56(2), 229.

Bastiampillai, T. J., Allison, S., Harford, P., Perry, S. W., \& Wong, M. L. (2019) Has the UK Improving Access to Psychological Therapies programme and rising antidepressant use had a public health impact? The Lancet Psychiatry 6(3), e8-e9.

Bostwick, W. B., Boyd, C. J., Hughes, T. L., West, B. T., \& McCabe, S. E. (2014) Discrimination and mental health among lesbian, gay, and bisexual adults in the United States. American Journal of Orthopsychiatry 84(1), 35.

Brennan, D. J., Ross, L. E., Dobinson, C., Veldhuizen, S., \& Steele, L. S. (2010) Men's sexual orientation and health in Canada. Canadian Journal of Public Health / Revue Canadienne de Sante'e Publique 101(3), 255-258.

Caceres, B.A., Travers, J., Primiano, J.E., Luscombe, R.E., Dorsen, C. (2019) Provider and LGBT Individuals' Perspectives on LGBT Issues in Long-Term Care: A Systematic Review. The Gerontologist. doi: 10.1093/geront/gnz012.

Castro, A. and Carnassale, D. (2019) Loving more than one color: Bisexuals of Color in Italy between stigma and resilience. Journal of Bisexuality 19, 198-228.

Clarke, V. \& Braun, V. (2017) Thematic analysis. The Journal of Positive Psychology 12(3), 297-298.

Chard, A. N., Finneran, C., Sullivan, P. S., \& Stephenson, R. (2015) Experiences of homophobia among gay and bisexual men: Results from a cross-sectional study in seven countries. Culture, Health \& Sexuality 17(10), 1174-1189.

D'Emilio, J. (2019) The history of sexuality: An assessment of the state of the field. History and Theory 58(1), 126-134.

Diamond, L. M. (2008) Female bisexuality from adolescence to adulthood: Results from a 10-year longitudinal study. Developmental Psychology 44(1), 5-14.

Dobinson, C., MacDonnell, J., Hampson, E., Clipsham, J., \& Chow, K. (2005) Improving the access and quality of public health services for bisexuals. Journal of Bisexuality 5(1), 39-77.

Eady, A., Dobinson, C. \& Ross, L. E. (2011) Bisexual people's experiences with mental health services: A qualitative investigation. Community Mental Health Journal, 47(4), 378389.

Ebersole, R.C., Dillon, F.R. \& Eklund, A.C. (2018) Mental Health Clinicians' Perceived Competence for Affirmative Practice with Bisexual Clients in Comparison to Lesbian and Gay Clients. Journal of Bisexuality 18(2), 127-144. 
Feinstein, B. A., \& Dyar, C. (2017) Bisexuality, minority stress, and health. Current Sexual Health Reports 9(1), 42-49.

Flanders, C.E., Shuler, S.A., Desnoyers, S.A. \& VanKim, N.A. (2019) Relationships between social support, identity, anxiety, and depression among young bisexual people of color. Journal of Bisexuality, 1-23.

Frost, D.M., Lehavot, K. \& Meyer, I.H. (2015) Minority stress and physical health among sexual minority individuals. Journal of Behavioral Medicine 38(1), 1-8.

Graneheim, U.H., Lindgren, B.M. \& Lundman, B. (2017) Methodological challenges in qualitative content analysis: A discussion paper. Nurse Education Today 56, 29-34.

Hafeez, H., Zeshan, M., Tahir, M. A., Jahan, N., Naveed, S. (2017) Health care disparities among lesbian, gay, bisexual, and transgender youth: A literature review. Cureus 9(4). doi: $10.7759 /$ cureus. 1184

Hickson, F., Davey, C., Reid, D., Weatherburn, P., Bourne, A. (2016) Mental health inequalities among gay and bisexual men in England, Scotland and Wales: A large community-based cross-sectional survey. Journal of Public Health 39(2), 266-273.

Hughes, T., Szalacha, L. A., \& McNair, R. (2010) Substance abuse and mental health disparities: Comparisons across sexual identity groups in a national sample of young Australian women. Social Science \& Medicine 71(4), 824-831.

la Roi, C., Meyer, I.H. \& Frost, D.M. (2019) Differences in sexual identity dimensions between bisexual and other sexual minority individuals: Implications for minority stress and mental health. American Journal of Orthopsychiatry 89(1), 40-51.

Lincoln, Y.S., \& Guba, E.G. (1985) Naturalistic Inquiry. California: Sage.

McCann, E. \& Brown, M. (2018) The inclusion of LGBT+ health issues within undergraduate healthcare education and professional training programmes: A systematic review. Nurse Education Today 64, 204-214.

McCann, E. \& Brown, M. (2019) The mental health needs and concerns of older people seniors who identify as LGBTQI+: A narrative review of the international literature. Journal of Advanced Nursing. https://doi.org/10.1111/jan.14193

McCann, E., Doyle, L., Keogh, B., Coyne, I. (2019) Healthcare issues and young people who identify as trans*: A scoping review. Youth and Society 51(6), 840-864.

McCann, E., \& Sharek, D. (2014) Survey of lesbian, gay, bisexual, and transgender people's experiences of mental health services in Ireland. International Journal of Mental Health Nursing 23(2), 118-127.

Miller, S. J., Mayo, C., \& Lugg, C. A. (2018) Sex and gender in transition in US schools: Ways forward. Sex Education 18(4), 345-359. 
Mollen, D., Burnes, T., Lee, S., \& Abbott, D. M. (2018) Sexuality training in counseling psychology. Counselling Psychology Quarterly. doi.org/10.1080/09515070.2018.1553146

National LGBT Health Education Center (2016) Affirmative Care for Transgender and Gender Non-Conforming People: Best Practices for Front-line Health Care Staff. Boston MA: The Fenway Institute.

Noble, H. \& Smith, J. (2015) Issues of validity and reliability in qualitative research. Evidence-based Nursing 18(2), 34-35.

Oginni, O. A., Mapayi, B. M., Afolabi, O. T., Obiajunwa, C., \& Oloniniyi, I. O. (2019) Internalized Homophobia, Coping, and Quality of Life Among Nigerian Gay and Bisexual Men. Journal of Homosexuality Apr 12:1-24. doi.org/10.1080/00918369.2019.1600899

Pepping, C. A., Lyons, A., \& Morris, E. M. (2018) Affirmative LGBT psychotherapy: Outcomes of a therapist training protocol. Psychotherapy 55(1), 52.

QSR International 2015. NVivo qualitative data analysis software; QSR International Pty Ltd. Version 11.

Rahman, M., Li, D.H. and Moskowitz, D.A. (2019) Comparing the Healthcare Utilization and Engagement in a Sample of Transgender and Cisgender Bisexual+ Persons. Archives of Sexual Behavior 48(1), 255-260.

Ross, L. E., Dobinson, C., \& Eady, A. (2010) Perceived determinants of mental health for bisexual people: A qualitative examination. American Journal of Public Health 100(3), 496.

Rostosky, S. S., Riggle, B. E., Pascale-Hague, D., \& McCants, L. (2010) The positive aspects of a bisexual self-identification. Psychology \& Sexuality 1(2), 131-144.

Savin-Williams, R.C. and Cohen, K.M. (2018) Prevalence, Mental Health, and Heterogeneity of Bisexual Men. Current Sexual Health Reports 10(3), 196-202.

Semlyen, J., King, M., Varney, J., \& Hagger-Johnson, G. (2016). Sexual orientation and symptoms of common mental disorder or low wellbeing: Combined meta-analysis of $12 \mathrm{UK}$ population health surveys. BMC Psychiatry 16(1), 67.

Sharek. D., Huntley-Moore, S. \& McCann, E. (2018) Education needs of families of transgender young people: A narrative review of international literature. Issues in Mental Health Nursing 39(1), 59-72.

Smith, R.W., Altman, J.K., Meeks, S., Hinrichs, K.L. (2018) Mental health care for LGBT older adults in long-term care settings: Competency, training, and barriers for mental health providers. Clinical Gerontologist, 1-6.

Steele, L., Ross, L., Dobinson, C., Veldhuizen, S., \& Tinmouth, J. (2009) Women's sexual orientation and health: Results from a Canadian population-based survey. Women \& Health 49(5), 353-367. 
Taylor, J. (2018) Bisexual Mental Health: A Call to Action. Issues in Mental Health Nursing 39(1), 83-92.

Taylor, J., Power, J., Smith, E., \& Rathbone, M. (2019) Bisexual mental health: 'Findings from the 'who I am 'study'. Australian Journal of General Practice 48(3), 138.

Van Beusekom, G., Bos, H.M., Kuyper, L., Overbeek, G. and Sandfort, T.G. (2018) Gender nonconformity and mental health among lesbian, gay, and bisexual adults: Homophobic stigmatization and internalized homophobia as mediators. Journal of Health Psychology 23(9), 1211-1222.

Voss, M. J. (2018). Contesting Sexual Orientation and Gender Identity at the UN Human Rights Council. Human Rights Review 19(1), 1-22.

Yoshino, K. (2000) The epistemic contract of bisexual erasure. Stanford Law Review 52(2), 353-461. 


\begin{tabular}{|c|c|c|c|c|c|c|c|}
\hline Respondent & $\begin{array}{l}\text { Age } \\
\text { range }\end{array}$ & $\begin{array}{l}\text { Gender } \\
\text { identity }\end{array}$ & $\begin{array}{l}\text { Partnership } \\
\text { status }\end{array}$ & Ethnicity & MH concerns & Interventions received & Services \\
\hline 9 & $45-64$ & Female & Single & Irish & Anxiety & $\begin{array}{l}\text { Psychotherapy } \\
\text { Family therapy }\end{array}$ & Outpatient \\
\hline 12 & $25-44$ & Male & Partnered & Non-Irish & Bipolar & Medication & Inpatient \\
\hline 14 & $18-24$ & Female & Single & Irish & $\begin{array}{l}\text { Anxiety } \\
\text { Depression } \\
\text { Sleep disorder }\end{array}$ & Medication & Outpatient \\
\hline 22 & $18-24$ & Male & Relationship & Irish & Depression & Medication & Outpatient \\
\hline 23 & $18-24$ & Female & Relationship & Irish & $\begin{array}{l}\text { Depression } \\
\text { Sleep disorder }\end{array}$ & $\begin{array}{l}\text { Medication } \\
\text { CBT }\end{array}$ & Inpatient \\
\hline 28 & $18-24$ & Female & Dating & Irish & Depression & Medication & Outpatient \\
\hline 29 & $18-24$ & Female & Relationship & Irish & $\begin{array}{l}\text { Anxiety } \\
\text { Depression } \\
\text { Sleep disorder } \\
\text { Substance use }\end{array}$ & $\begin{array}{l}\text { Psychotherapy } \\
\text { Art therapy }\end{array}$ & Outpatient \\
\hline 30 & $25-44$ & Female & Single & Irish & $\begin{array}{l}\text { Depression } \\
\text { Eating disorder }\end{array}$ & Medication & Outpatient \\
\hline 56 & $18-24$ & Female & Relationship & Irish & $\begin{array}{l}\text { Anxiety } \\
\text { Depression } \\
\text { Obsessive } \\
\text { Compulsive } \\
\text { Disorder (OCD) }\end{array}$ & $\begin{array}{l}\text { Medication } \\
\text { CBT } \\
\text { Family therapy }\end{array}$ & Outpatient \\
\hline
\end{tabular}




\begin{tabular}{|c|c|c|c|c|c|c|c|}
\hline & & & & & Sleep disorder & & \\
\hline 81 & $45-64$ & $\begin{array}{l}\text { Trans } \\
\text { Female }\end{array}$ & Single & Irish & Depression & Medication & Outpatient \\
\hline 84 & $25-44$ & Female & Single & Irish & $\begin{array}{l}\text { Depression } \\
\text { Eating disorder }\end{array}$ & Medication & Inpatient \\
\hline 89 & $18-24$ & $\begin{array}{l}\text { Trans } \\
\text { Male }\end{array}$ & Relationship & Non-Irish & $\begin{array}{l}\text { Gender identity } \\
\text { disorder }\end{array}$ & Counselling & Outpatient \\
\hline 96 & $25-44$ & Female & Single & Irish & Anxiety & $\begin{array}{l}\text { Mindfulness } \\
\text { Family therapy }\end{array}$ & Outpatient \\
\hline 107 & $25-44$ & Male & Dating & Irish & Depression & $\begin{array}{l}\text { Medication } \\
\text { CBT } \\
\text { Mindfulness }\end{array}$ & Inpatient \\
\hline 110 & $25-44$ & Male & Single & Irish & $\begin{array}{l}\text { Anxiety } \\
\text { Depression }\end{array}$ & Medication & Outpatient \\
\hline 114 & $25-44$ & Female & Single & Irish & $\begin{array}{l}\text { Depression } \\
\text { Eating disorder } \\
\text { Substance use }\end{array}$ & Medication & $\begin{array}{l}\text { Inpatient } \\
\text { Outpatient }\end{array}$ \\
\hline 119 & $18-24$ & Male & Single & Irish & $\begin{array}{l}\text { Bipolar } \\
\text { Depression } \\
\text { Obsessive } \\
\text { Compulsive } \\
\text { Disorder (OCD) }\end{array}$ & Medication & $\begin{array}{l}\text { Inpatient } \\
\text { Outpatient }\end{array}$ \\
\hline 122 & $25-44$ & Male & Single & Irish & $\begin{array}{l}\text { Depression } \\
\text { Sleep disorder }\end{array}$ & Medication & Outpatient \\
\hline 124 & $45-64$ & Female & Single & Irish & $\begin{array}{l}\text { Anxiety } \\
\text { Depression }\end{array}$ & Medication & Outpatient \\
\hline
\end{tabular}


